\title{
Obstacles for Chinese EFL Learners to Master English Subjunctive Mood
}

\author{
Zewei Wei ${ }^{1, *}$ \\ ${ }^{1}$ Shandong University, Jinan, Shandong, China \\ ${ }^{*}$ Corresponding author. Email:201903071138@mail.sdu.edu.cn
}

\begin{abstract}
By error analysis and contrastive analysis, this study critically explores the obstacles preventing Chinese EFL learners from mastering English subjunctive mood. Based on the data of a questionnaire about Chinese students' acquisition of English subjunctive mood, the study firstly reconfirms the previous finding that Chinese EFL learners have the ability of reasoning counterfactually. Secondly, the study gives explanations to different errors of Chinese EFL learners, including intralingual errors, interlingual errors and cognitive errors. Finally, the results show that most of the intralingual errors of Chinese EFL learners are caused by overgeneralization. The interlingual errors are mainly due to negative transfers from Chinese. Additionally, cognitive errors are made because Chinese EFL learners have a special understanding of the formality and metaphoricity of English subjunctive mood.
\end{abstract}

Keywords: English subjunctive mood, Chinese EFL learners, Error analysis, Obstacles.

\section{INTRODUCTION}

Nowadays, in this increasingly globalized world, English plays an important role in international communication. In 2019, the EF English Proficiency Index shows that "more than a billion people speak English as a first or second language, and hundreds of millions more as a third or fourth" [1]. Moreover, a global language survey carried out in 2013 indicates that a country's economic power, per capita income level and residents' life quality are positively correlated with its residents' English language proficiency [2]. Under this circumstance, to conduct international exchanges and cooperation and then to boost the development of economy and society, it is necessary for China to develop English education.

Chinese English education is complicated, spanning a wide range of ages starting from primary school students to graduated students. Moreover, it involves various fields such as vocabulary, grammar and pronunciation. Among them, grammar teaching is one of the most significant aspects of Chinese English education. As Fengjuan Wang said in the Necessity of Grammar Teaching, "mastering grammar is the foundation in the proficiency of a language" [3]. In addition, it is worth mentioning that the grammar taught in Chinese English education system refers to prescriptive grammar instead of descriptive grammar.
In addition, the grammar system is also highly complex. David Crystal estimated that there are about 3500 grammar rules in the English language [4]. English grammar teaching in China generally follows the order from general to special and from simple to complex. After mastering basic grammar principles firstly, Chinese EFL learners will next learn difficult principles and some exceptions, and finally put these principles into practice. Among these rules, one of the most difficult aspects for Chinese EFL learners to master is English subjunctive mood which is a grammatical construction describing a non-actual scenario by changing the form of a verb in a finite clause. In order to help Chinese EFL learners grasp English subjunctive mood, this essay will focus on the obstacles in their study process.

The reason why Chinese EFL learners cannot grasp English subjunctive mood is not a new topic. It has been studied by many linguistics and psychologists. Since English subjunctive mood is a grammatical construction to depict counterfactual situations, the earlier studies often focused on whether Chinese EFL learners have the ability of counterfactual thinking. In 1981, Bloom conducted an experiment to illustrate that there is no linguistic mark in Chinese for expressing counterfactual ideas [5]. However, his point of view was criticized by other linguists and philosophers due to the fact that most of other experiments showed that Chinese people had 
the ability of counterfactual reasoning and their performance was similar to those English speakers' [6-9]. "Despite all these criticisms, Bloom's work captured the imagination of the public and scholars alike, in part because no one can explain how Chinese speakers could reason counterfactually without a language that supports it [10]." However, recent studies indicated that "Chinese language provided both lexical and syntactical devices to mark counterfactuals" [10]. Additionally, Jing-Schmidt Zhuo further took a constructionist approach to counterfactual language in Chinese, putting forward three typical counterfactual constructions in Chinese, including the [yaobushi $\mathrm{X}, \mathrm{Y}$ ] construction, the [COND X, zaojiu Y] construction and the [ruguo zao X, Y] construction [11]. The existence of these counterfactual expressions in Chinese language not only successfully offered an explanation for the phenomena that Chinese-speakers can think counterfactually like English-speakers, but also proved Bloom's conclusion wrong. Consequently, the previous studies showed that no counterfactual thinking ability was not the reason why Chinese EFL learners cannot master English subjunctive mood, because they actually had counterfactual expressions in their language. As the result, the real cause of the difficulty in learning English subjunctive mood for Chinese EFL learners is still unknown. In this situation, this study firstly reconfirms the finding of the previous studies that Chinese-speaking people do have the ability to reason counterfactually and then explores other possible obstacles for Chinese EFL learners to grasp English subjunctive mood.

This study uses Error Analysis as the main method for discussion. In his book, Introducing Second Language Acquisition, Muriel Saville-Troike says, "Error Analysis is the first approach to the study of second language acquisition which includes an internal focus on learners' creative ability to construct language. It is based on the description and analysis of actual learner errors in second language, rather than on idealized linguistic structures attributed to native speakers of first language and second language [12]."

As Ellis illustrated in his book, The Study of Second Language Acquisition, Error Analysis consists of the following five steps: (1) collection of a sample of learner language, (2) identification of errors, (3) description of errors, (4) explanation of errors, and (5) evaluation of errors [13]. Consequently, the discussion part of this study will mainly follow these steps.

The reason why this study choose Error Analysis as the major method for analysis is that as S. Pit Corder pointed out, second language learners' errors should not be regarded as "bad habits" to be eradicated, but as valuable sources for understanding the learning processes. He claimed that through errors, we can get access to the language learners use in the course of second language development and see the strategies learners use in second language acquisition. Further, he regarded making errors as "a way the learner has of testing his hypothesis about the nature of the language he is learning [14]." That is to say, by making errors learners can know whether they understand the usage of second language correctly or not. Therefore, in this study, errors made by Chinese EFL learners are precious and will be seen as the main object of analysis.

In addition, according to Corder, the purpose of Error Analysis is to find "what the learner knows and does not know" and to "ultimately enable the teacher to supply him not just with the information that his hypothesis is wrong, but also, importantly, with the right sort of information or data for him to form a more adequate concept of a rule in the target language [15]". As a result, by using Error Analysis, this study will be meaningful and influential for the development of the English Education in China.

This study also uses Contrastive Analysis as one approach to analyze the data collected. Contrastive Analysis is "an approach to the study of second language acquisition which involves predicting and explaining learner problems based on a comparison of first language and second language to determine similarities and differences [12]".

This theory is based on the "contrastive hypothesis" put forward by Lado, whose opinion is that "we can predict and describe the patterns that will cause difficulty in learning, and those that will not cause difficulty, by comparing systematically the language and culture to be learned with the native language and culture of the student [16]." In other words, the differences between second language and first language will lead to difficulties in second language acquisition, while the similarities will be beneficial to the acquisition. Based on this hypothesis, another assumption of this theory is that when learners study second language, there will be a transfer from their first language. When the same structure is appropriate to both languages, the transfer is called a positive transfer. However, when the structure of first language is applied inappropriately in second language, the transfer is negative.

Since this study is about Chinese EFL learners' acquisition of English subjunctive mood, Contrastive Analysis is necessary for comparing the Chinese counterfactual expressions and English subjunctive structures. By using Contrastive Analysis, this study is able to examine whether there are some negative transfers from Chinese language preventing Chinese EFL learners from mastering English subjunctive mood.

In summary, the obstacles for Chinese EFL learners to master English subjunctive mood is complex and multifaceted. Based on the abovementioned literature, although more research has emerged recently on 
Chinese counterfactual thinking ability, the current research is still messy and limited for figuring out the real obstacles. The difficulties preventing Chinese EFL learners from mastering English subjunctive mood is still not clear and comprehensive, so the purpose of this article is to systematically and clearly analyze the obstacles for Chinese EFL learners to master English subjunctive mood by error analysis and contrastive analysis.

\section{METHODS}

The study uses a questionnaire as the means of survey and takes error analysis and contrastive analysis as the approaches to analyze the data.

\subsection{Questionnaire}

The name of the questionnaire is "A Survey of Chinese Students' English Acquisition" and it is designed via the platform Credamo. The expected respondents for it are Chinese university students. It is issued from 23 August to 26 August, 2021.

The questionnaire can be divided into 4 parts, consisting of 10,10, 20 and 11 questions respectively. The first part includes 5 groups of questions. Each group has two single-choice questions. The first single-choice question provides a situation in Chinese where English subjunctive mood should be used when translating this situation into English. There are 4 options provided for the single-choice question: "use English subjunctive mood", "not use English subjunctive mood", "not sure" and "I don't know". The following question offers a change of the situation given in the single-choice question and askes the respondents to choose their answers again. The change is made in status, emotion, factuality and other aspects. The second part also has 5 groups of questions, and each group has one single-choice question and one fill-in-the-blank question. The single-choice question is the same as the first question in the first part. By contrast, unlike the second question in the first part, the fill-in-blank question asks directly for the reasons why the respondents choose to use or not use English subjunctive mood in the first question of this part. The third part consists of 10 fill-in-the-blank questions, which ask the respondents to translate the Chinese sentences given in a specific context into English. Finally, the last part has 11 questions aiming to collect some personal information of the respondents, such as gender, age, educational background and their attitudes towards English subjunctive mood.

The scenes used in the questions above come from the grammar book A Guide to English Grammar for Middle School Students by Guo [17], therefore, the quality and correctness of applied scenes related to subjunctive mood can be guaranteed.
This study collects 209 samples, of which 208 are valid. There are 111 female, 95 male, and 2 other gender respondents. Their average age is $20( \pm 1)$. Among them, 190 respondents are undergraduate students, whereas 18 are currently studying at the postgraduate level.

\subsection{Error Analysis}

In this study, Error Analysis is used as a major approach to explore the obstacles for Chinese EFL learners to learn English subjunctive mood.

We will generally follow the five steps mentioned in the introduction, which includes (1) collection of a sample of learner language, (2) identification of errors, (3) description of errors, (4) explanation of errors, and (5) evaluation of errors [13]

\subsection{Contrastive Analysis.}

As introduced in introduction, Contrastive Analysis is also a significant way of analyzing the data collected.

The study compares the difference between Chinese and English, in terms of vocabulary, grammar and structure. Based on the comparison, the study points out negative transfers from Chinese to English, which causes the obstacles in Chinese EFL learners' study of English.

\section{DATA AND ANALYSIS}

\subsection{Data}

As the method part illustrates, there are 4 types of questions in the questionnaire for this study, including scene change questions, reason collection questions, translation questions and personal opinion questions. Consequently, the data is exposed according to the question categories.

\subsubsection{Scene Change Questions}

In questions Q19-20, a scenario for a job interview is provided. The specific situation is that when you and your boss listen to the self-introduction of a secretary candidate, the interviewee says he or she usually help his or her roommates tidy up things. And you say to your boss, “我建议可以马上录用这个秘书。” According to the grammar book A Guide to English Grammar for Middle School Students, the correct translation of this Chinese sentence should be "I think it advisable that a secretary be appointed at once [17]." This standard translation corresponds to one of the rules of English subjunctive mood which is when speakers give advice, infinitives should be used in object clauses. In this situation, the respondents are asked in Q19 that if they need to translate this Chinese sentence into English, whether they will use English subjunctive mood. Further, 
in Q20, the respondents are asked that if the same Chinese sentence is said by your boss to you, whether they will choose to use English subjunctive mood. Finally, as figure 1 shows, in Q19, among 206 respondents, 147 persons choose not to use English subjunctive mood, while 44 people choose to use it. Other 15 respondents choose other options including "not sure" and "I don't know". In contrast, in Q20, as figure 2 indicates, the number of people who will not use English subjunctive mood decreases dramatically into 65 , while that of people who choose to use it increases to 124. Meanwhile, 17 respondents choose other answers.

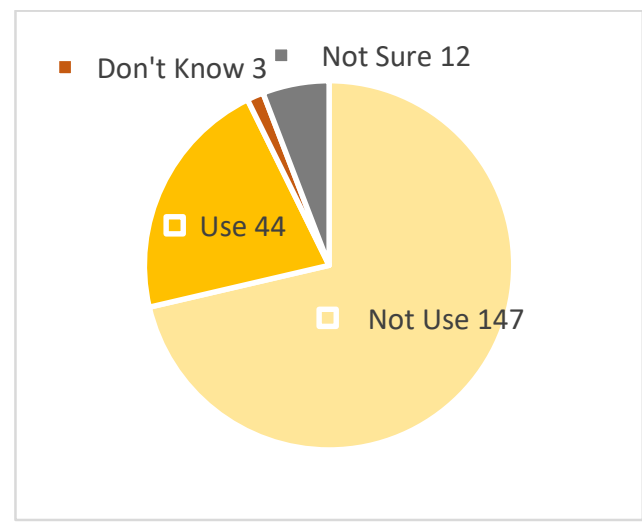

Figure 1. Data of Q19

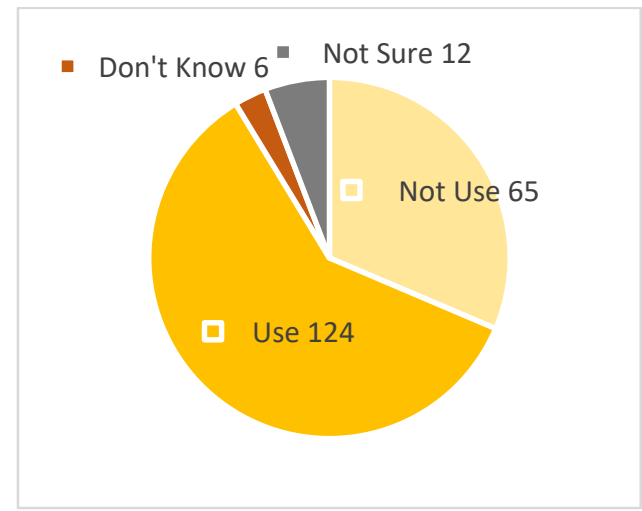

Figure 2. Data of Q20

In question Q25-26, the situation is that a teacher, pointing at Xiaoming who always submits his homework on time, says to the principle, “即便他经常 不交作业, 他的成绩也一直都很好。” As the grammar book suggests, the standard translation of this Chinese sentence should be "his grades were always excellent, even though he often failed to hand in his homework", which applies English subjunctive mood [17]. In Q25, the respondents are asked to decide whether to use English subjunctive mood or not when translating the Chinese sentence into English. In Q26, the respondents are asked that if Xiaoming indeed always fails to submit his homework, whether they will change their decision. As the result shown in figure 3, in Q25, among 206 respondents, 49 people decide not to use English subjunctive mood, while 148 people decide to use it. Conversely, according to figure 4, in Q26, 179 respondents choose not to use English subjunctive mood and only 18 people choose to use it.

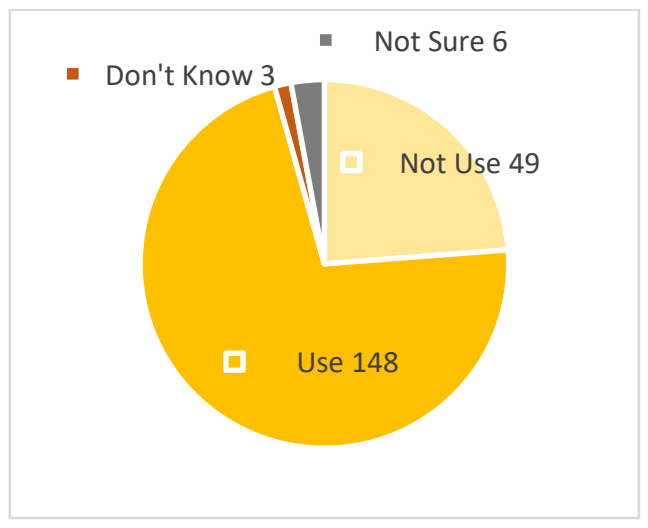

Figure 3. Data of Q25

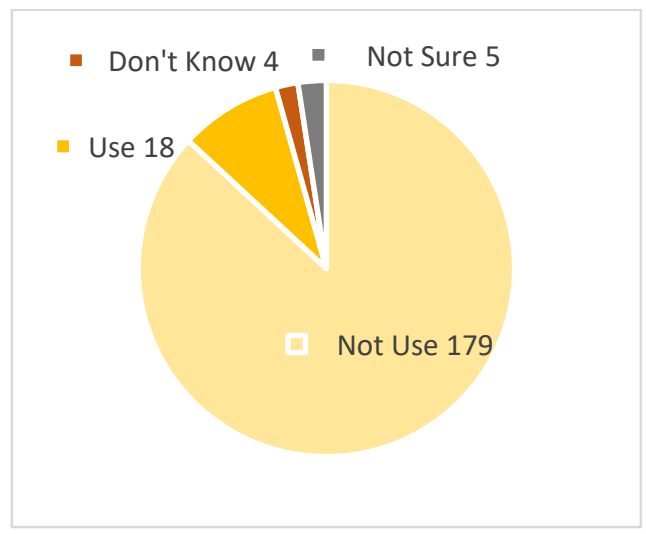

Figure 4. Data of Q26

\subsubsection{Reason Collection Questions}

In question Q10-11, the respondents are invited to think of a situation that when your boyfriend asks you to drink more hot water, you say to your friend, “他好像把 我当小孩儿一样说话。” The standard translation of this sentence should be "he talks to me as though I were a child", which reflects the rule of English subjunctive mood which is to indicate a deviation from the reality by using "were" [17]. In Q10, the respondents are asked to choose whether to use English subjunctive mood when translating this Chinese sentence into English and are asked the reasons for their decisions in Q11. The results are shown in figure 5-7. In Q10, among 206 respondents, $51 \%$ of them choose not to use English subjunctive mood, while $43 \%$ of them choose to use it. Other $6 \%$ of them choose "I don't know" or "not sure". In Q11, people illustrate their reasons for their answers in Q10. For people who choose to use English subjunctive mood, $85 \%$ of them use it because they regard the sentence as a counterfactual expression. At the same time, 3\%, $6 \%$ and another $6 \%$ of them make their decision according to their language intuition, the tone of the sentence and the Chinese markers of English subjunctive mood in the 
sentence respectively. On the other hand, for the people who choose not to use English subjunctive mood, $60 \%$ of them choose not to use it because they see the sentence not as counterfactual. Meanwhile, 14\%, 10\%, $8 \%$ and another $8 \%$ of them make their judgement according to their language intuition, the colloquiality of the sentence, the metaphor in the sentence and the tone of the sentence respectively.

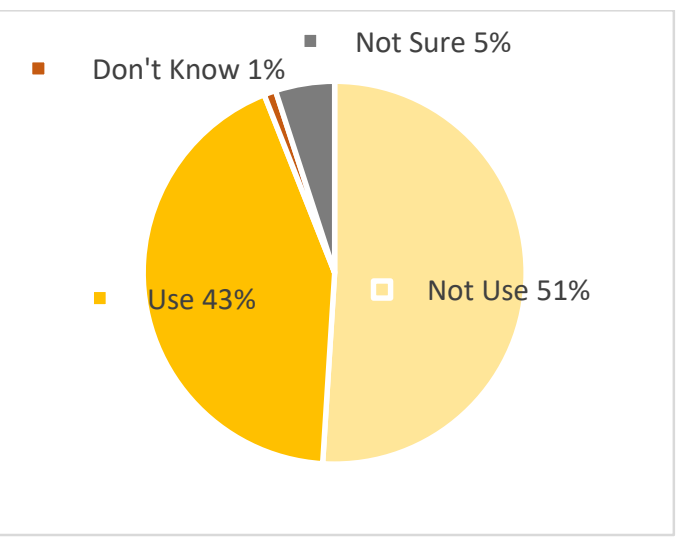

Figure 5. Respondents' Decisions in Q10

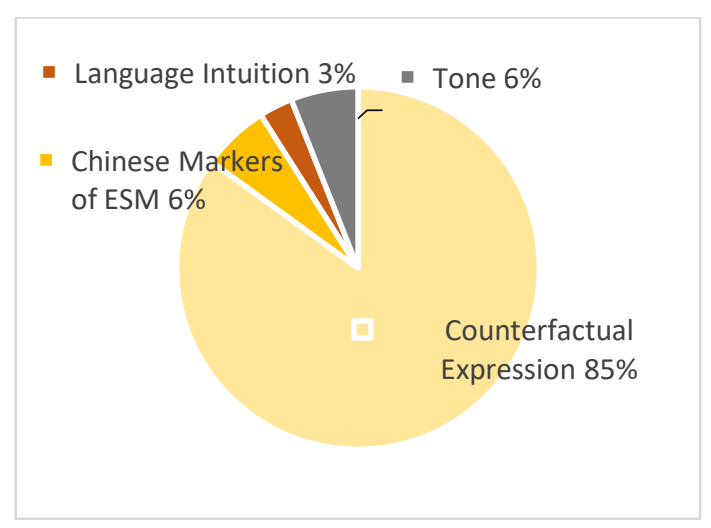

Figure 6. Reasons for using ESM

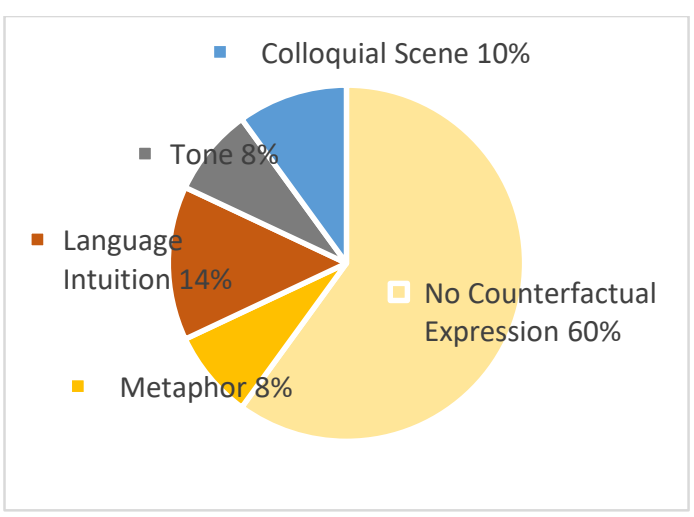

Figure 7. Reasons for not using ESM

\subsubsection{Translation Questions}

In question Q3, the respondents are asked to imagine a situation that when Xiaohong wants to call a staff of a study abroad agency who used to tell Xiaohong his telephone number, she finds that she has deleted it. Therefore, she says to you, “我真希望我能记得他的手 机号。” The respondents are asked to translate this Chinese sentence into English. The results collected are exhibited in table 1. The standard translation from the grammar book should be "I wish I knew his phone number", which can be further generalized into the pattern "I wish I did..." [17]. On the contrary, the data shows that $65 \%$ of the respondents choose to translate the sentence into "I wish I could remember...", while 18\% of them uses a similar pattern, which is "I hope (that) I could remember...". Only $6 \%$ of the respondents uses the pattern "I wish I remembered...", which corresponds to the right pattern of the standard translation.

Table 1. Data of Q3

\begin{tabular}{|l|l|l|l|}
\hline Chinese Version & Standard Translation & Patterns & Frequency \\
\hline $\begin{array}{l}\text { 我真希望我能记 } \\
\text { 得他的手机号。 }\end{array}$ & $\begin{array}{l}\text { I wish I knew his } \\
\text { phone number. }\end{array}$ & I wish I could remember... & $65 \%$ \\
\cline { 3 - 4 } & I hope (that) I could remember... & $18 \%$ \\
\cline { 3 - 4 } & I wish I remembered... & $6 \%$ \\
\cline { 3 - 4 } & I wish I could have remembered... & $4 \%$ \\
\cline { 3 - 4 } & Other patterns & $7 \%$ \\
\hline
\end{tabular}

In question Q18, the situation provided is that Xiaoming, who is a dead beat, says to you, "if you treat me this time, I will treat you for the next two times." You say, “我宁愿我们这次各自付账。” The respondents are asked to translate this sentence into English. The standard translation is "I would rather we went Dutch", which can be further generalized into "I would rather somebody did..." [17]. As table 2 indicates, only $2 \%$ of the respondents used English subjunctive mood in the standard way, but $71 \%$ of them uses the pattern "I would rather we go Dutch..." and $13 \%$ of them use "I would rather go Dutch...". In the meantime, $7 \%$ of them use the patterns of "prefer", including "I prefer to go Dutch...", "I prefer (that) we go Dutch..." and "I prefer going Dutch...". Interestingly, $1 \%$ of them uses the pattern "I wish we could go Dutch...". The rest $6 \%$ of them choose other patterns. 
Table 2. Data od Q18

\begin{tabular}{|l|l|l|l|}
\hline Chinese Version & Standard Translation & Patterns & Frequency \\
\hline $\begin{array}{l}\text { 我宁愿我们这次 } \\
\text { 各自付账。 }\end{array}$ & $\begin{array}{l}\text { I would rather we went } \\
\text { Dutch. }\end{array}$ & I would rather we go Dutch... & $71 \%$ \\
\cline { 3 - 4 } & I would rather go Dutch... & $13 \%$ \\
\cline { 3 - 4 } & $\begin{array}{l}\text { I prefer to go Dutch.../I prefer (that) we } \\
\text { go Dutch.../I prefer going Dutch... }\end{array}$ & $7 \%$ \\
\cline { 3 - 4 } & I would rather (that) we went Dutch... & $2 \%$ \\
\cline { 3 - 4 } & I wish we could go Dutch... & $1 \%$ \\
\cline { 3 - 4 } & Other patterns & $6 \%$ \\
\hline
\end{tabular}

In question Q21, the situation offered is that when you are short of money, you ask Xiaoming about the bank loan. Xiaoming suggests you borrow some money from Xiaogang. You say, “要是太阳从西边升起, 他就 会把钱借给我。” Similarly, the respondents need to translate the Chinese part into English. The standard pattern should be "if the sun were to rise in the west, he would lend me the money." The data in table 3 shows respondents' word choice in the "if-clause". Only 4\% of the respondents use the standard pattern, while $36 \%$ of them use "if the sun rises...". Moreover, 23\% of them use "if the sun rose..." and $21 \%$ of them use "if the sun would rise...". $13 \%$ of them choose to use "if the sun will rise...". The rest $3 \%$ of them choose other patterns.

Table 3. Data of Q21

\begin{tabular}{|l|l|l|}
\hline If-clause & Predicate & Frequency \\
\hline \multirow{3}{*}{ If the sun... } & Rises & $36 \%$ \\
\cline { 2 - 3 } & Rose & $23 \%$ \\
\cline { 2 - 3 } & Would rise & $21 \%$ \\
\cline { 2 - 3 } & Will rise & $13 \%$ \\
\cline { 2 - 3 } & Were to rise & $4 \%$ \\
\cline { 2 - 3 } & Others & $3 \%$ \\
\hline
\end{tabular}

\subsubsection{Personal Opinion Questions}

In Q2-9, the respondents are asked directly whether English subjunctive mood may be used even when the sentence describes a fact. The data is shown in table 4 . $41 \%$ of the respondents choose "yes" and $19 \%$ of them choose "definitely yes". In contrast, $13 \%$ of them choose "not quite right" and $2 \%$ of them choose "definitely no". The rest $25 \%$ choose "not sure".

Table 4. Data of Q2-9

\begin{tabular}{|l|l|}
\hline Options & Frequency \\
\hline Definitely Yes & $19 \%$ \\
\hline Yes & $41 \%$ \\
\hline Not Sure & $25 \%$ \\
\hline
\end{tabular}

\begin{tabular}{|l|l|}
\hline Not Quite Right & $13 \%$ \\
\hline Definitely No & $2 \%$ \\
\hline
\end{tabular}

In Q2-10, the question is if it is possible to not use English subjunctive mood even when the sentence is a counterfactual expression. As table 5 shows, $56 \%$ of the respondents choose "yes" and $23 \%$ of them choose "definitely yes". In the meantime, $4 \%$ of them choose "not quite ok" and $1 \%$ of them choose "definitely no". The rest $16 \%$ of them choose "not sure".

Table 5. Data of Q2-10

\begin{tabular}{|l|l|}
\hline Options & Frequency \\
\hline Definitely Yes & $23 \%$ \\
\hline Yes & $56 \%$ \\
\hline Not Sure & $16 \%$ \\
\hline Not Quite Ok & $4 \%$ \\
\hline Definitely No & $1 \%$ \\
\hline
\end{tabular}

\subsection{Analysis}

\subsubsection{Reconfirmation of Previous Findings}

The data of Q25-26 indicates that when a sentence describes a reality, most of Chinese EFL learners will not use English subjunctive mood, but when the sentence is changed into a counterfactual expression, most of them will use English subjunctive mood. This result shows that most of Chinese EFL learners can make their judgment of whether using English subjunctive mood or not according to the factuality of a sentence. This conclusion reconfirms the previous finding of linguistics and philosophers that Chinese EFL learners have the ability to recognize counterfactual patterns in a language [6-9].

\subsubsection{Error Analysis}

Based on the data collected, the study divides the errors made by Chinese EFL learners into intralingual 
errors, interlingual errors and cognitive errors.

\subsubsection{Intralingual Errors}

In Q18, the respondents fail to follow the correct pattern of translation. Instead, most of them use the incorrect pattern "I would rather we go Dutch...". The study contributes this error of the respondents to overgeneralization. Overgeneralization is defined as "the use of previously available strategies in new situations" [18]. When answering Q18, most of the respondents fail to use the past tense in the object clause because they mix up the rule "would rather + do" and the rule "would rather + an object clause". In the rule "would rather + do", the phrase "would rather" can be regarded as a modal auxiliary verb, after which a verb must be in the infinitive. However, the rule "would rather + an object clause" is a rule of English subjunctive mood. According to the Dictionary of English Usage, when "would rather" is followed by an object clause, the object clause should be in subjunctive mood, which means the clause predicate need use the past tense to express the present or future, and the past perfect to express the past [19]. For example, in the sentence "I would rather you went home now", the past tense of the verb "go" is used to indicate one action in the present. If the respondents confuse the two rules, they will use infinitives in the object clauses after "would rather", which is what the respondents do when answering Q18. Therefore, this study points out that the reason why most of the respondents use the incorrect pattern "I would rather we go Dutch..." is overgeneralization.

\subsubsection{Interlingual Errors}

In Q3, instead of applying the standard rule "I wish I did...", most of the respondents use "I wish I could do...". In English subjunctive mood, in the object clause following "wish", the predicate should be used in the past tense to indicate the present activities. Conversely, in the incorrect pattern "I wish I could do...", the respondents add a modal verb "could" in the object clause, which results in the loss of the past tense of the predicate. In this study, the reason why the respondents add a modal verb into the clause is contributed to the negative transfer from Chinese language. This is because in the Chinese sentence provided in the question, there is a Chinese character "能”, which is frequently used in Chinese to indicate that the subject is capable of finishing the action described by the predicate. The word “能” not only serves a similar function to the English word "can", but also has a similar meaning to it. If the respondents translate the Chinese sentence word by word, they will inevitably use the word "can" in the object clause. Moreover, the word "could" can be seen as the past version of "can". As the result, when they try to apply the word "can" into the rule "I wish I did...", they will change "can" into "could" and then add it into the object clause.

There is another interlingual error made in Q21. In Q21, the correct pattern of the "if-clause" is "if the sun were to rise...", which uses one past version of the copula "be" to indicate the content of this sentence is counterfactual. However, $70 \%$ of the respondents fail to use any past tense in the "if-clause". Instead, they uses "rises", "will rise" and "would rise", which are in the simple present tense or the simple future tense. This is due to the difference between English and Chinese, which can also be seen as a negative transfer from Chinese language. In English subjunctive mood, it is typical to use the past tense to indicate the counterfactuality of a sentence. However, different from English, "Chinese is thought of as a 'tenseless' language whose temporal location is expressed directly by adverbials and indirectly by the use of aspectual viewpoint" [20]. Consequently, influenced by the negative transfer from their native language, Chinese EFL learners usually fail to apply the past tense when using English subjunctive mood.

\subsubsection{Cognitive Errors}

Based on the data, it is found that in some circumstances where English subjunctive mood need to be applied, many respondents will choose not to use it. This kind of misjudgments can be regarded as cognitive errors. That is to say, Chinese EFL learner fail to use English subjunctive mood appropriately because they have cognitive misunderstandings of it. This statement can be proved by Q2-9 and Q2-10. In Q2-9, most of the respondents believe that English subjunctive mood can be used even when the sentence describes a fact. In Q2-10, most of them insist that even when a sentence is counterfactual, it is possible to not apply English subjunctive mood in it. However, according to the prescriptive grammar, when expressing a purely imaginary situation or a subjective wish, English subjunctive need to be applied [21]. The answers of the two questions show that most of Chinese EFL learners have a vague understanding of the usable range of English subjunctive mood. Based on the data, this study divides Chinese EFL learners' cognitive errors into two aspects including formality and metaphoricity of English subjunctive mood.

Q19-20 reflects Chinese EFL learners' cognition of the formality of English subjunctive mood. When the Chinese sentence provided is said by a staff to his or her boss, most of the respondents will choose not to use English subjunctive mood, but when the same sentence is said by a boss to a staff, most of them will choose to use it. This interesting phenomenon can be related to Chinese EFL learners' cognition of the formality of English subjunctive mood. In other words, they choose to use English subjunctive mood when talking to people with higher status because they regard English 
subjunctive mood as a formal way of speaking. In consequence, in order to show their respect, they choose to use English subjunctive mood. However, in the aspect of prescriptive grammar, English subjunctive mood is applied according to the factuality of the situations and the emotion of the speakers, instead of the formality of the situation. In this way, the errors in cognition leads to the errors in usage.

Evidence can also be found in Q10-11. The data shows that a group of the respondents believe that in colloquial scenes, there should not be English subjunctive mood.

In Q10-11, respondents show their understanding of the metaphoricity of English subjunctive mood. A group of them hold the opinion that when a sentence is a metaphor, it should not use English subjunctive mood. This indicates that some Chinese EFL learners see English subjunctive mood as an expression with low metaphoricity, which can interrupt the beauty of a metaphor. A possible explanation is that when people use metaphors, they try to trigger associations of ideas. However, the English subjunctive mood usually uses explicit markers, like the past tense, to show that the content of a sentence is counterfactual. In this way, if a speaker applies English subjunctive mood in a metaphorical sentence, the markers of subjunctive mood will stop the associations of the listeners or readers by telling them directly that the what they hear or read is fake. As the result, the low metaphoricity which is attached to English subjunctive mood by Chinese EFL learners can prevent them from using English subjunctive mood in metaphorical situations.

\section{CONCLUSION}

Through analyzing the reasons behind the errors of Chinese EFL learners, this study not only further verifies the claim that Chinese EFL learners have the same ability to recognize counterfactual expressions as English speakers but also finds obstacles for Chinese EFL learners to learn English subjunctive mood. The first obstacle is overgeneralization, which will lead learners to mix up the patterns of English subjunctive mood and other English patterns. The errors caused by overgeneralization are intralingual errors. Another obstacle is the negative transfers from Chinese language, which will result in interlingual errors in Chinese EFL learners' use of English subjunctive mood. The last obstacle is Chinese EFL learners' inappropriate cognition of the formality and metaphoricity of English subjunctive mood, which is the reason why many Chinese EFL learners make cognitive errors when using English subjunctive mood. However, the results of this study are limited since most of the participants are college students. For future studies, it will be better to include Chinese EFL learners from different age groups as their study objects and compare the mastery of
English subjunctive mood between learners of different periods.

\section{REFERENCES}

[1] E. F. E. P. Index, (2020). EF EPI A Ranking of 100 Countries and Regions by English Skills. Official Document on-line. Document retrieved on 16/9/2021.

[2] ICEF MONITOR. (2014, January 29). Global language survey links English proficiency to economic and social developments. ICEF GmbH. https://monitor.icef.com/2014/01/global-language-s urvey-links-english-proficiency-to-economic-and-s ocialdevelopment/.

[3] F. Wang, (2010). The Necessity of Grammar Teaching. English Language Teaching, 3(2), 78-81.

[4] D. Crystal, (2006). The Fight for English: How language pundits ate, shot, and left. Oxford University Press.

[5] B. A. Elman, (1983). The Linguistic Shaping of Thought: A Study in the Impact of Language on Thinking in China and the West. By Alfred Bloom. Hillsdale, NJ: Erlbaum Associates, 1981. 106 pp. Appendix, Index. \$16.95. The Journal of Asian Studies, 42(3), 611-614.

[6] T. K. Au, (1983) Chinese and English counterfactuals: The Sapir-Whorf hypothesis revisited. Cognition, 15(1-3), 155-187.

[7] L. G. Liu, (1985). Reasoning counterfactually in Chinese: Are there any obstacles? Cognition, 21(3), 239-270.

[8] C. H. F. Wu, (1993). " If triangles were circles...,": A study of counterfactuals in Chinese and in English. Harvard University.

[9] D. Yeh, \& D. Gentner, (2005). Reasoning counterfactually in Chinese: Picking up the pieces. In Proceedings of the Twenty-seventh Annual Meeting of the Cognitive Science Society (Vol.27, No. 27).

[10] G. Feng, \& L. Yi, (2006). What if Chinese had linguistic markers for counterfactual conditionals? Language and thought revisited. In Proceedings of the Annual Meeting of the Cognitive Science Society (Vol. 28, No. 28).

[11] Z. Jing-Schmidt, (2017). What are they good for? A constructionist account of counterfactuals in ordinary Chinese. Journal of Pragmatics, 113, 30-52. 
[1][12] Corcilius, Klaus. "Ideal Intellectual Cognition in Tim. 37a2-c5. ” 2017.

[13] R. Ellis, \& R. R. Ellis, (1994). The study of second language acquisition. Oxford University.

[14] S. P. Corder, (1967). The significance of learners' errors. IRAL, 5, 161-170.

[15] S. P. Corder, (1974). Error Analysis: Perspectives on second language acquisition. London: Longman.

[16] R. Lado, (1957). Linguistics Across Cultures: Applied Linguistics for Language Teachers. University of Michigan Press.

[17] F. Guo, (2018). A Guide to English Grammar for Middle School Students. Shanghai: Fudan University Press.

[18] B. S. Schwarte, (1981). The acquisition of English sentential complementation by adult speakers of Finnish (Doctoral dissertation, University of Illinois at Urbana-Champaign).

[19] B. Bing, \& W. Fuzhen, (2009). The Dictionary of English Usage. Commercial Press.

[20] T. Zhang, (2013). An Output-guided Study of Chinese Students' ESA Difficulty. Journal of Language Teaching and Research, 4(4), 874-883.

[21] D. Z. Zang, (1979). A practical English grammar. Commerce Press. 